\title{
The effect of caring work environment model on nurses' burnout in general hospitals
}

\author{
Kuswantoro Rusca Putra ${ }^{1}$, Heriandi Sutadi ${ }^{2}$, Setyowati ${ }^{3}$, Rr. Tutik Sri Hariyati ${ }^{4}$ \\ ${ }^{1}$ Departement of Nursing Management, Faculty of Medicine, Brawijaya University, Malang, Indonesia \\ ${ }^{2}$ Faculty of Dentistry, University of Indonesia, Depok, Indonesia \\ ${ }^{3,4}$ Faculty of Nursing, University of Indonesia, Depok, Indonesia
}

\begin{tabular}{l} 
Article Info \\
\hline Article history: \\
Received Dec 19, 2020 \\
Revised May 14, 2021 \\
Accepted Jun 11, 2021 \\
\hline
\end{tabular}

\section{Keywords:}

Depersonalization

Emotional exhaustion

Nurse work environment

Personal-accomplishment

\begin{abstract}
Nurses belong to a profession that carries a high risk of burnout. This condition will have an impact on the performance and quality of nursing services. Efforts should be made to minimize burnout for nurses. Management of the nurses' work environment is one that should be done by the nurse manager. This study aimed to identify the effect of the implementation of a caring work environment by the head of the care unit on nurse burnout. This study used a quasi-experimental design with a pre- and post-test with control group approach. Respondent of this study was 170 nurses who were divided into intervention and control groups. The intervention group consisted of nurses within the Caring Work Environment Model as applied by the head of the units. The control group included nurses working in the environment commonly applied in accordance with hospital policies in the inpatient unit. Burnout measurements on nurses applied preand post- intervention. Data analysis was performed using the Mann Whitney test. This research showed a decrease in emotional fatigue and depersonalization scores, and an increase in nurse personal accomplishment, $(\mathrm{p}<0.001)$ after the implementation of the nurse's caring work environment model by the head of care unit in the intervention group. Within the control group, only personal accomplishment showed increased scores, $(\mathrm{p}=0.034)$. Reduction in burnout symptoms in nurses can be facilitated through the implementation of a caring work environment by the head of the care unit.
\end{abstract}

This is an open access article under the CC BY-SA license.

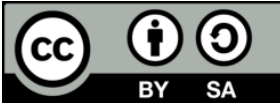

\section{Corresponding Author:}

Kuswantoro Rusca Putra

Department of Nursing Management, Faculty of Medicine

Universitas Brawijaya

Jalan Veteran Malang, East Java, Indonesia

Email: torro.fk@ub.ac.id

\section{INTRODUCTION}

Nurse occupations have high work demands including work routines, excessive workload, tight work schedules, responsibility for the safety and health of themselves and others and are required to be able to work in teams. This condition causes nurses to be very susceptible to stress at work [1], [2]. The high stress that must be faced by nurses increases their susceptibility to burnout [3], [4]. The results of research in several countries show that the prevalence of burnout in the high category occurs in nurses working in hospitals [5], [6]. Research conducted at several hospitals in East Java Province showed that nurses experiencing emotional exhaustion, depersonalization, and decreased achievement of high personal achievement categories were found with a prevalence of more than 24\% [7]. Burnout in nurses has an impact 
on unexpected events in patients [8]. This condition, if not managed properly, will have an impact on the condition and performance of nurses and the quality of service received by patients.

The organizational environment is a factor that contributes to the nurses' burnout [9]. There are six areas of work environment that influence burnout, namely workload, control, respect, fairness, community and workplace values [2], [10]. Organizational management and work environment efforts can be made to prevent nurse burnout [11]. A good nurse work environment is characterized by high quality leadership and management, adequate staff, positive nurse-doctor relationships, reasonable workloads and the right working conditions needed to ensure and maintain high quality patient care [12]-[14].

Some studies mention that nurses within a good work environment report a decrease in burnout symptoms [15]-[17]. Improving the nurse's work environment from poor to better can reduce burnout due to work for nurses [18]. The nurse's work environment in the hospital can be perceived as unfavorable resulting in nurses having no enthusiasm at work, frequent disputes and dissatisfaction, and feeling helpless when carrying out their responsibilities [19]. This condition indicates that there is a need for good management of the work environment in order to reduce the incidence of burnout and its negative impact on nurses.

Management of the work environment requires input from the ward leader. Leadership in the care unit has an important role in creating a good work environment [20]. Nurse leaders and staff have the responsibility to develop a healthy work environment where nursing staff have the ability to communicate and interact openly, positively and consistently with the authority and ethics of their profession [21]. The role of the leader or nurse manager is very influential in creating a work environment that supports caring nursing practices [22]. The caring behavior displayed by the leader or nurse manager should include the behavior of recruiting staff willing to the existence of a nurse manager, advancing staff through a desire to help staff succeed, developing staff capacity that supports individual potential, helping staff to develop and forming connections or bonding with staff [23], [24]. These conditions show the importance of the behavior of the head of the care unit in managing a good nurse work environment in the workplace. Based on the above explanation, it is necessary to conduct research to determine the effect of proactive management on the nurse's work environment by the head of the care unit on nurse burnout.

\section{RESEARCH METHOD}

This study used a quasi-experimental design with a pre- and post-test with control group approach. The research sample in this study comprised 170 nurses. The sampling technique was simple random sampling in the medical surgical wards at two government-owned public hospitals in East Java Province. The study sample was divided into two groups, namely the intervention and the control group. Each group consisted of 85 nurses in nine care units with nine nurse managers as head of the units. The control group functioned within the nurse's work environment that is commonly applied in accordance with hospital policies in the inpatient units. The intervention group functioned within the Caring Work Environment Model applied by the head of the units. The heads of the inpatient units were trained using the Caring Work Environment Model modules such as nurse manager caring behavior module (120 minutes); workload management module (120 minutes); nurse control management module (120 minutes); and reward management module (120 minutes). Assistance after the training in the application of the work environment module was provided for 12 days. After that, the nurse managers implemented the model for one month. Burnout measurements for nurses were obtained before and after the implementation of the model.

Nurse burnout data collection was based on the maslach burnout inventory-human service survey (MBI-HSS) instrument [7]. Respondents answered questions on the MBI-HSS questionnaire by writing down the numbers in accordance with their experience on the seven choices of rating scale ranging from $1=$ "never" to 7="every day". The number of questions was 20 with details to enable measurement of emotional exhaustion (eight items), depersonalization (four items) and personal accomplishment (eight items). The data from this study was found to be not normally distributed so the Mann Whitney test was implemented. The Mann Whitney test was used to test differences in emotional fatigue, depersonalization and decreasing achievement of the nurses in the intervention and control groups. This study was approved via ethical clearance from the Ethical Committee in Health Research Dr. Soetomo General Hospital Surabaya No. 0314/KEPK/V/2018. All respondents who participated in this study had received a full study explanation and provided informed consent.

\section{RESULTS AND DISCUSSION}

Characteristics and equality tests of respondents between the intervention and control groups were based on sex, employment status, age and length of employment. The characteristics of the respondent nurses and the results of the equality test are illustrated in Table 1. Based on Table 1 the results indicate no 
significant difference in respondent characteristics between the intervention and control groups. The results of the analysis of differences in burnout, (emotional exhaustion, depersonalization, decreased personal accomplishment) on the nurses after the analysis of the intervention and control groups is also shown. An explanation of the reduction in burnout score is illustrated in Table 2. Table 2 shows differences in mean burnout scores, (emotional exhaustion, depersonalization, decreased personal accomplishment) in the intervention group $(\mathrm{p}<0.001)$. Whereas, in the control group there were differences in mean burnout scores but only a significant decrease in personal accomplishment. The influence of the nurse's work environment on emotional exhaustion, depersonalization and the decrease in achievement also needs to consider the role of confounding variables. Variables estimated as confounding in this study include age, sex, marital status, education level and length of employment. The following Table explains the analysis of the effect of confounding variables on the dependent variables, (emotional exhaustion, depersonalization and decreased achievement). From Table 3, it can be seen that the variables of age, sex, marital status, education and length of employment ( $p>0.05)$ as confounding variables do not affect emotional exhaustion, depersonalization and decreased achievement. This proves that changes in emotional fatigue scores, depersonalization and decreased achievement in measurements after intervention are not caused by age, sex, marital status, education and length of employment. They are more closely related to the improvement of the nurses' work environment by the head of the care unit.

Table 1. Characteristics of respondents equality test

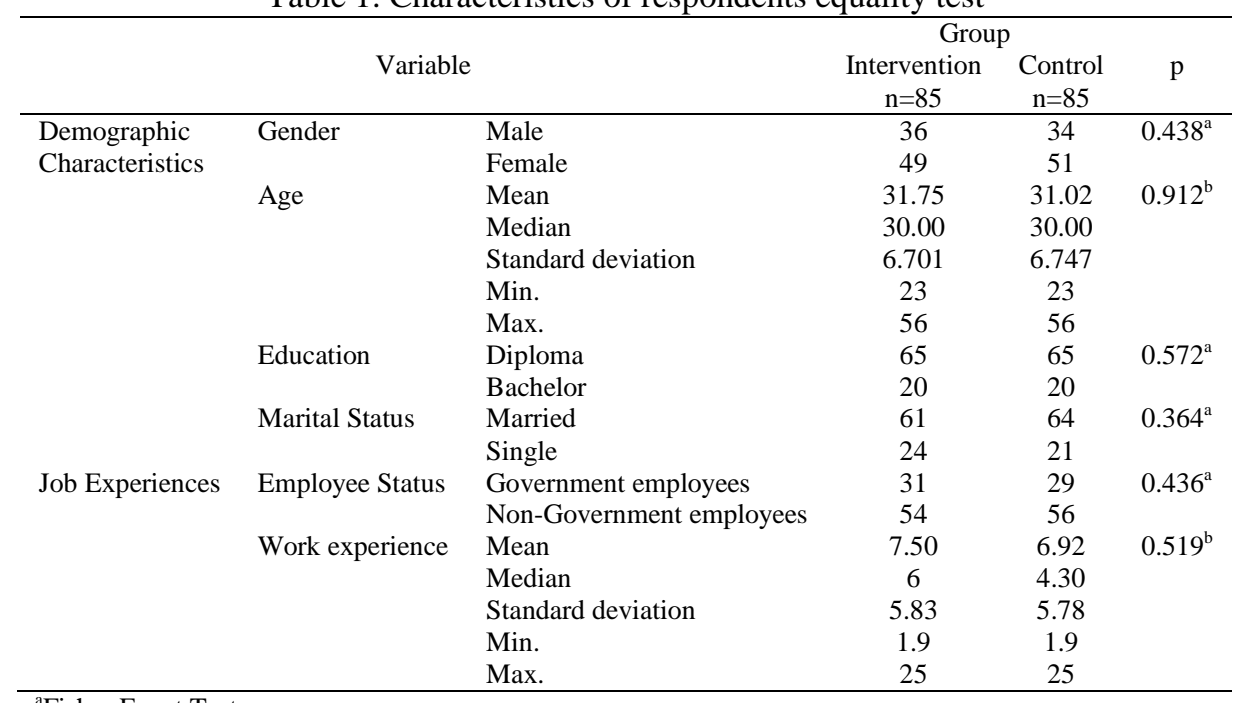

${ }^{\mathrm{a}}$ Fisher Exact Test

${ }^{\mathrm{b}}$ Anova Test

Table 2. Differences in emotional exhaustion, depersonalization, reduced personal accomplishment on intervention and control group $(\mathrm{n}=170)$

\begin{tabular}{lccc}
\multicolumn{1}{c}{ Variable } & Mean & & $\mathrm{p}$ \\
\hline Emotional exhaustion & Before & After & 0.103 \\
$\quad$ Control group & & & $<0.001$ \\
$\quad$ Intervention group & 23.94 & 23.60 & 0.355 \\
Depersonalization & 24.55 & 18.40 & $<0.001$ \\
$\quad$ Control group & 12.28 & 12.40 & 0.034 \\
$\quad$ Intervention group & 10.69 & 8.24 & $<0.001$ \\
Reduced personal accomplishment & & & 0.040 \\
$\quad$ Control group & 23.12 & 22.39 & $<0.001$ \\
$\quad$ Intervention group & 22.21 & 17.82 & 58.39 \\
$\quad$ \\
Burnout total
\end{tabular}


Table 3. The effect of confounding factor to nurses' burnout

\begin{tabular}{cccc}
\hline Confounding variable & Emotional exhaustion & Depersonalization & Reduced personal accomplishment \\
\hline Age & $0.680^{\mathrm{a}}$ & $0.895^{\mathrm{a}}$ & $0.793^{\mathrm{a}}$ \\
Gender & $0.484^{\mathrm{b}}$ & $0.480^{\mathrm{b}}$ & $0.480^{\mathrm{b}}$ \\
Marital status & $0.636^{\mathrm{b}}$ & $0.845^{\mathrm{b}}$ & $0.221^{\mathrm{b}}$ \\
Education & $0.761^{\mathrm{b}}$ & $0.433^{\mathrm{b}}$ & $0.394^{\mathrm{b}}$ \\
Work & $0.912^{\mathrm{a}}$ & $0.682^{\mathrm{a}}$ & $0.739^{\mathrm{a}}$ \\
experience & & & \\
\hline${ }^{\mathrm{a}}$ Pearson test & & & \\
bearman rho test & &
\end{tabular}

\subsection{Emotional exhaustion}

The nursing caring work environment is a work model implemented by the head ward using the eight caring factor approach to manage nurses' control of their practice, workload and rewards. This model takes the form of assistance and direct application by the head of the ward in order to reduce emotional fatigue, depersonalization and increase the achievement of the nurses' performance. This research proves that the management of nurses' work environment contributes to a reduction in emotional fatigue. Improvement of the work environment in some hospitals can reduce the incidence of burnout symptoms by $5 \%$ in the high category [25]. Other studies have found that a poor work environment has an impact on the high emotional fatigue of nurses [17]. The leadership style of the head of the ward is an environmental factor that protects nurses against emotional exhaustion. Only transformational leadership styles show a tendency to predict the emotional exhaustion of nurses with a negative correlation between transformational leadership and emotional exhaustion [26]. Leadership style was integrated in this study to assess the implementation of the eight caring behaviors by the heads of the inpatient units.

Workload is a factor that can predict the increase in average or high emotional fatigue in nurses [27]. This study proves that the efforts made by the head of the inpatient unit by applying this model through organizing the provision of care to patients, by dividing nurses working in teams covering three shifts, make it easier for nurses to complete their tasks. In addition, nurses who are only on permanent duty in one team, found it easier to delegate work in order to complete their tasks. This result is in agreement with other research which showed that the average emotional fatigue in the inpatient room using the team method is lower compared with other methods of providing nursing care [28].

Scheduling services with nurses changing shifts patterns after a minimum of two days and having two days off after a night shift is also felt to be sufficient to restore the normal body biorhythms of nurses and can reduce emotional exhaustion experienced by nurses. The average score of nurses' emotional fatigue on a rotating service schedule, is lower than nurses with fixed service schedules. Work shift patterns are therefore factors that influence the occurrence of emotional exhaustion in nurses [28]. This result is in accordance with several studies which found that the reduction in workload that was previously excessive has a strong correlationship with a reduction in emotional fatigue [28]-[30].

Nurses who have limited work autonomy are associated with emotional exhaustion and reduced interest in tasks or activities [31]. Other studies suggest that the limitations of autonomy and the low ability of nurses to control their practice can increase emotional fatigue [32]. The decrease in the average score of nurses' emotional fatigue in this study could also be due to the management of controls in the intervention group through allocating work in accordance with their clinical authority. Enforcement of clinical authority for nurses ensures that there is clarity about the duties and responsibilities of nurses when carrying out their duties. Control is a need for professional autonomy, clarity of roles and access to the necessary resources [10].

Rewards is a predictive factor for the occurrence of emotional fatigue in nurses. The results of other studies have found that increasing imbalance in rewards can increase emotional exhaustion [33]. The decrease in the average score of nurses' emotional fatigue in this study could also be due to the management of rewards conducted by the head of the inpatient unit. This result is in accordance with several other studies which concluded that appreciation has an influence on emotional exhaustion, the better the appreciation in the workplace, the lower the emotional fatigue [30], [34].

\subsection{Depersonalization}

An unfavorable work environment will have an impact on the incidence of nurses experiencing high depersonalization [17]. The results of other studies indicated that a poor nurses' work environment in hospitals could result in nurses lacking enthusiasm at work, frequent disputes and dissatisfaction, and feeling powerless when carrying out their responsibilities [19]. The results of statistical tests in this study indicate that the application of the nurse work environment model in the intervention group was able to significantly reduce depersonalization of nurses pre- and post-test $(\mathrm{p}<0.001)$. The mean reduction in depersonalization scores 
was 2.05 in the intervention group. The results of this study are in accordance with another study which showed that improving the work environment in several hospitals reduced the incidence of high category burnout [25].

The head of the inpatient unit, in their role as a leader, is largely responsible for the application of the nurses' work environment. Another study concluded that there is a negative relationship between transformational leadership and depersonalization of nurses; the better the leadership, the less depersonalization experienced by nurses [26]. Other research also highlighted that staff management carried out by the head of the unit directly affects the depersonalization experienced by nurses [35]. Nurses who work in hospitals with a better working environment are significantly associated with a decrease in depersonalization [15]. The decrease in mean depersonalization scores for nurses can be linked to the workload management carried out by the head of the unit. These results are consistent with another study which stated that the nurses' practice environment through workload mediation influences the depersonalization of nurses [36].

Some studies suggest that the limitations of nurse autonomy have an impact on depersonalization of nurses [37]. The another study demonstrated that low control possessed by nurses and inferior rewards are associated with an increased incidence of depersonalization among nurses [29].

The decrease in mean depersonalization scores for nurses in this study could also be attributed to the positive management of awards performed by the head of the nursing unit. In an unfavorable work environment, nurses will experience a high decline in self-achievement [17]. The results of statistical tests in this study showed that the application of the nurse work environment in the intervention group was able to significantly improve nurses' personal accompishment. These results are consistent with another study which found that a significantly better work environment has a strong correlationship with increased achievement of nurses [15].

\subsection{Personal accomplishment}

Research conducted by Zhang et al. states that a poor work environment could cause nurses to experience a high decrease in self-achievement by up to $52.52 \%$ [17]. The results of statistical tests in this study showed that the application of a nursing caring work environment model in the intervention group was able to significantly increase nurses' levels of achievement. The increase in nurse achievement was significant before and after application of this intervention model. The average score for the achievement of nurses achievement was 4.39 in the intervention group. These results are in accordance with another study which stated that a better work environment has a significant relationship with an increase in nurse achievement [15].

The increased score for self-achievement among nurses can be attributed to the caring behavior of the head of the unit. These results are consistent with other research which showed that leadership has a positive correlation with workload, control, community, respect, justice and values [29]. Leadership is the starting point in the work environment model and influences all other work environment factors. Without positive leadership, other aspects in the work environment are less effective in contributing toward positive nurse outcomes [11]. The results of this study are also in agreement with the another study which found that leaders are an important factor in creating a work environment that supports the professional practice of nurses [20]. The results of this study show that caring behavior positively affects the decrease in nurse achievement. This result aligns other research which found that there is an influence between poor leader behavior and decreased achievement among nurses. The better the leader's behavior, the more nurses' achievement will increase [11].

Several studies indicate that there is a positive correlation between leadership style and personal accomplishment among nurses' [26], [28]. Improving the quality of care delivered by nurses is significantly related to increasing achievement [13]. The increase in the achievement score is thought to have occurred because the reward management was carried out by the head of the unit.

This study found that confounding factors including gender, marital status, age, education level, length of employment do not significantly influence emotional exhaustion, depersonalization and decreased achievement. It was statistically proven in this research that a decrease in emotional fatigue scores, depersonalization, and reduced decline in achievement can be attributed to the application of the caring approach to the nurses' work environment by the head of the unit. The limitations of the study are family problems and incidental conditions that occur in the room such as code blue incidents. A sudden increase in the number of patients may have an impact on burnout experienced by nurses because they are not controlled during the implementation of the model.

\section{CONCLUSION}

Proper management of nurses' work environment has a positive influence on the symptoms of burnout. Namely decreased emotional fatigue, decreased depersonalization and increased achievement compared to before treatment. This research recommends is that the Caring Work Environment Model can be 
used as a basis for developing policies for hospital management and professional organizations. It positively addresses workload, nurse control and rewards for application in hospitals in an effort to meet hospital accreditation standards related to nursing staff management. This research can be applied in different clinical care settings in order to improve the robustness of the application of this model by adding individual personality type variables and nurses' abilities to cope with stress.

\section{ACKNOWLEDGEMENTS}

This study was funded by Directorate Research and Community Services Universitas Indonesia Hibah Tadok 2018 No.1260/UN2.R3.1/HKP.05.00/2018. Thank you very much to the respondents involved in this research.

\section{REFERENCES}

[1] S. J. Tucker, A. J. Weymiller, S. M. Cutshall, L. M. Rhudy, and C. M. Lohse, "Stress ratings and health promotion practices among RNs: A case for action,” J. Nurs. Adm., vol. 42, no. 5, pp. 282-292, 2012.

[2] C. Dall'Ora, J. Ball, M. Reinius, P. Griffiths, and P. Griffiths, "Burnout in nursing: A theoretical review," Hum. Resour. Health, vol. 18, no. 1, pp. 1-17, 2020.

[3] Z. Xie, A. Wang, and B. Chen, "Nurse burnout and its association with occupational stress in a cross-sectional study in Shanghai," J. Adv. Nurs., vol. 67, no. 7, pp. 1537-1546, 2011.

[4] K. Rusca Putra and Setyowati, "Prevalence of burnout syndrome among nurses in general hospitals in provincial East Java: Cross-sectional study," Enferm. Clin., vol. 29, 2019.

[5] V. F. Ribeiro et al., "Prevalence of burnout syndrome in clinical nurses at a hospital of excellence," Int. Arch. Med., vol. 7, no. 1, pp. 1-7, 2014.

[6] S. Rezaei, B. Karami Matin, M. Hajizadeh, A. Soroush, and B. Nouri, "Prevalence of burnout among nurses in Iran: a systematic review and meta-analysis," Int. Nurs. Rev., vol. 65, no. 3, pp. 361-369, 2018.

[7] K. Rusca Putra and Setyowati, "Prevalence of burnout syndrome among nurses in general hospitals in provincial East Java: Cross-sectional study," Enferm. Clin., vol. 29, no. May 2020, pp. 362-366, 2019.

[8] X. Liu et al., "Hospital nursing organizational factors, nursing care left undone, and nurse burnout as predictors of patient safety: A structural equation modeling analysis," Int. J. Nurs. Stud., vol. 86, pp. 82-89, 2018.

[9] N. McCormack and C. Cotter, "Managing Burnout in the Workplace: A guide for information professionals," New Delhi: Chandos Publishing, 2013.

[10] K. R. Putra, H. Sutadi, S. Setyowati, and R. T. S. Hariyati, "The impact of nurse manager caring behaviors and work environment on burnout syndrome among nurses," Kontakt, vol. 23, no. 2, pp. 90-96, 2021

[11] R. W. Liao, M. L. Yeh, K. C. Lin, and K. Y. Wang, "A Hierarchical Model of Occupational Burnout in Nurses Associated with Job-Induced Stress, Self-Concept, and Work Environment," J. Nurs. Res., vol. 28, no. 2, pp. 1-9, 2020.

[12] N. M. Solomons and J. A. Spross, "Evidence-based practice barriers and facilitators from a continuous quality improvement perspective: An integrative review," J. Nurs. Manag., vol. 19, no. 1, pp. 109-120, 2011.

[13] B. Li et al., "Group-level impact of work environment dimensions on burnout experiences among nurses: A multivariate multilevel probit model," Int. J. Nurs. Stud., vol. 50, no. 2, pp. 281-291, 2013.

[14] P. Lambrou, A. Merkouris, N. Middleton, and E. Papastavrou, "Nurses' perceptions of their professional practice environment in relation to job satisfaction: A review of quantitative studies," Heal. Sci. J., vol. 8, no. 3, pp. 298$317,2014$.

[15] A. Nantsupawat, W. Kunaviktikul, R. Nantsupawat, O. A. Wichaikhum, H. Thienthong, and L. Poghosyan, "Effects of nurse work environment on job dissatisfaction, burnout, intention to leave," Int. Nurs. Rev., vol. 64, no. 1, pp. 91-98, 2017.

[16] P. Copanitsanou, N. Fotos, and H. Brokalaki, "Effects of work environment on patient and nurse outcomes," Br. J. Nurs., vol. 26, no. 3, pp. 172-176, 2017.

[17] L. feng Zhang et al., "The association of Chinese hospital work environment with nurse burnout, job satisfaction, and intention to leave," Nurs. Outlook, vol. 62, no. 2, pp. 128-137, 2014.

[18] K. Liu et al., "The relationship between hospital work environment and nurse outcomes in Guangdong, China: A nurse questionnaire survey," J. Clin. Nurs., vol. 21, no. 9-10, pp. 1476-1485, 2012.

[19] A. Maziah, O. Wichaikhum, and R. Nantsupawat, "Nursing Practice Environment and Patient Outcomes in University Hospitals in Malaysia," Heal. Environ. J., vol. 3, no. 1, pp. 16-26, 2012.

[20] M. A. Roche, H. K. S. Laschinger, and C. Duffield, "Testing the Nursing Worklife Model in Canada and Australia: A multi-group comparison study," Int. J. Nurs. Stud., vol. 52, no. 2, pp. 525-534, 2015.

[21] J. R. Duffy, Quality caring in nursing and health professions: Implication for clinicians, educators, and leaders implication for clinicians, educators, and leaders third edition, New York: Springer Publishing Company. pp. 238239, 2018.

[22] C. M. Cara, J. J. Nyberg, and S. Brousseau, "Fostering the coexistence of caring philosophy and economics in today's health care system," Nurs. Adm. Q., vol. 35, no. 1, pp. 6-14, 2011.

[23] A. Oluma and M. Abadiga, "Caring behavior and associated factors among nurses working in Jimma University specialized hospital, Oromia, Southwest Ethiopia, 2019," BMC Nurs., vol. 19, no. 1, pp. 1-7, 2020. 
[24] L. Olender, "The Relationship between and Factors Influencing Staff Nurses' Perceptions of Nurse Manager Caring and Exposure to Workplace Bullying in Multiple Healthcare Settings," J. Nurs. Adm., vol. 47, no. 10, pp. 501-507, 2017.

[25] A. Kutney-Lee, E. S. Wu, D. M. Sloane, and L. H. Aiken, "Changes in hospital nurse work environments and nurse job outcomes: An analysis of panel data," Int. J. Nurs. Stud., vol. 50, no. 2, pp. 195-201, 2013.

[26] R. Madathil, N. C. Heck, and D. Schuldberg, "Burnout in Psychiatric Nursing: Examining the Interplay of Autonomy, Leadership Style, and Depressive Symptoms," Arch. Psychiatr. Nurs., vol. 28, no. 3, pp. 160-166, 2014.

[27] K. Mcmillan et al., "Burnout and the provision of psychosocial care amongst Australian cancer nurses," Eur. J. Oncol. Nurs., vol. 22, pp. 37-45, 2016.

[28] R. H. Mudallal, M. Y. N. Saleh, H. M. Al-Modallal, and R. Y. Abdel-Rahman, "Quality of nursing care: The influence of work conditions, nurse characteristics and burnout," Int. J. Africa Nurs. Sci., vol. 7, pp. 24-30, 2017.

[29] H. K. S. Laschinger, L. Borgogni, C. Consiglio, and E. Read, "The effects of authentic leadership, six areas of worklife, and occupational coping self-efficacy on new graduate nurses' burnout and mental health: A crosssectional study," Int. J. Nurs. Stud., vol. 52, no. 6, pp. 1080-1089, 2015.

[30] K. Nishimura et al., "Cross-sectional survey of workload and burnout among japanese physicians working in stroke care the nationwide survey of acute stroke care capacity for proper designation of comprehensive stroke center in japan (j-aspect) study," Circ. Cardiovasc. Qual. Outcomes, vol. 7, no. 3, pp. 414-422, 2014.

[31] C. Kowalski et al., "Burnout in nurses-the relationship between social capital in hospitals and emotional exhaustion," J. Clin. Nurs., vol. 19, no. 11-12, pp. 1654-1663, 2010.

[32] M. R. Panunto and E. de B. Guirardello, "Professional nursing practice: Environment and emotional exhaustion among intensive care nurses," Rev. Lat. Am. Enfermagem, vol. 21, no. 3, 2013.

[33] A. Loerbroks, H. Meng, M. L. Chen, R. Herr, P. Angerer, and J. Li, "Primary school teachers in China: associations of organizational justice and effort-reward imbalance with burnout and intentions to leave the profession in a crosssectional sample," Int. Arch. Occup. Environ. Health, vol. 87, no. 7, pp. 695-703, 2014.

[34] H. T. T. Nguyen, K. Kitaoka, M. Sukigara, and A. L. Thai, "Burnout Study of Clinical Nurses in Vietnam: Development of Job Burnout Model Based on Leiter and Maslach's Theory," Asian Nurs. Res. (Korean. Soc. Nurs. Sci)., vol. 12, no. 1, pp. 42-49, 2018.

[35] N. Khamisa, B. Oldenburg, K. Peltzer, and D. Ilic, "Work related stress, burnout, job satisfaction and general health of nurses," Int. J. Environ. Res. Public Health, vol. 12, no. 1, pp. 652-666, 2015.

[36] P. Van Bogaert, S. Clarke, R. Willems, and M. Mondelaers, "Nurse practice environment, workload, burnout, job outcomes, and quality of care in psychiatric hospitals: A structural equation model approach," J. Adv. Nurs., vol. 69, no. 7, pp. 1515-1524, 2013.

[37] C. Fernet, S. Austin, S. G. Trépanier, and M. Dussault, "How do job characteristics contribute to burnout? Exploring the distinct mediating roles of perceived autonomy, competence, and relatedness," Eur. J. Work Organ. Psychol., vol. 22, no. 2, pp. 123-137, 2013. 